IRA-International Journal of Education \& Multidisciplinary Studies

ISSN 2455-2526; Vol.07, Issue 03 (2017)

Pg. no. 200-209

Institute of Research Advances

http://research-advances.org/index.php/IJEMS

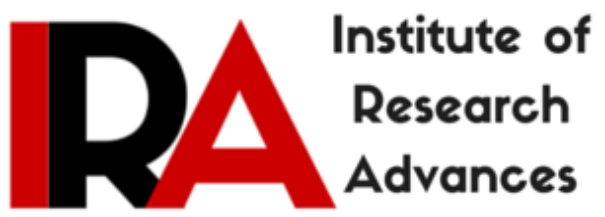

\title{
Learning for Healthy Food Habit: Avoiding Junk Foods
}

\author{
Suchandra Samanta Mandal ${ }^{1,2}$, Deb Prasad Sikdar ${ }^{1}$ \\ ${ }^{1}$ Department of Education, University of Kalyani, Pin - 741 235, West Bengal, India \\ ${ }^{2}$ Krishnanagar B.Ed. College, P.O. Krishnanagar, Dist. Nadia, West Bengal, India.
}

Type of Review: Peer Reviewed.

DOI: http://dx.doi.org/10.21013/jems.v7.n3.p4

\section{How to cite this paper:}

Mandal, S., \& Sikdar, D. (2017). Learning for Healthy Food Habit: Avoiding Junk Foods. IRA International Journal of Education and Multidisciplinary Studies (ISSN 2455-2526), 7(3), 200209. doi:http://dx.doi.org/10.21013/jems.v7.n3.p4

(C) Institute of Research Advances.

\section{(cc) BY-NC}

This work is licensed under a Creative Commons Attribution-Non Commercial 4.0 International License subject to proper citation to the publication source of the work.

Disclaimer: The scholarly papers as reviewed and published by the Institute of Research Advances (IRA) are the views and opinions of their respective authors and are not the views or opinions of the IRA. The IRA disclaims of any harm or loss caused due to the published content to any party. 


\section{ABSTRACT}

Dietary behavior is very important for the growth and development of human beings. Nutritional status of an individual is highly influenced by varied eating patterns. In recent years there is a tendency of excessive intake of dietary fats and sugars in comparison to fruits and vegetables. Especially children and adolescents are getting more and more addicted to junk foods and fast foods and pursuing an unhealthy food habit. The adults have also fallen prey to this menace. The consequences are obesity, various physical and mental complications, learning disorders, etc. This paper is aimed at finding out the actual reasons behind such problem and how it can be solved. Informal and formal learning may have profound effect in this regard. Children, youth and adults need to realize that they are vulnerable to rapidly changing world and have to learn how to cope with it. For this they require continuous building up of practical knowledge, attitude, skills and motivation that will lead them to a healthy lifestyle or healthy living.

Key words: Dietary behavior, junk food, healthy food habit.

\section{Introduction}

Genes primarily regulates some aspects of our health and vitality (http://www.bbc.co.uk/science/0/22019289), but dietary behaviour including other lifestyle factors are important for our ability to live a long and healthy life. Nutritional status of an individual is highly influenced by varied eating patterns. The eating pattern of individual first gained attention in western countries, then it propagated to developing countries as well including India in recent years claiming that they have a skewed diet-pattern. Particular areas of concern are intake of excessive dietary fats in comparison to fruits and vegetables. Owing to globalization and urbanization, in developing countries, eating behavior of an individual is now increasingly coming under the spotlight. According to WHO, nearly $2 / 3$ rd of premature deaths and $1 / 3$ rd of total disease burden in adults are associated with conditions or behavior that began in their youth, including food habit, a lack of physical activity etc.

Although, snacks can be a source of required nutrients and calories, but it can lead to overweight too. Obesity brings other diseases like juvenile diabetes, tooth decay, gastrointestinal problems, and strokes in later life. Numerous additives are added to junk foods to enhance the taste, color, flavor or preserve for a longer period. One such example is mono-sodium-glutamate (MSG). It is a flavor enhancer commonly added to Chinese food, canned vegetables, soups, and processed meats that cause hypothyroidism, headache, and nausea, difficulty in breathing, drowsiness, rapid heartbeat and chest pain (Schaumburg, et.al., 1969).

Promotion of healthy lifestyle is required to reduce health risks in young age and adulthood. For this, proper learning is necessary. Learning is the desirable modification of behavior. Learning begins at birth and through various experiences encountered in the course of a lifetime it continues to build skills and knowledge throughout our lives. Children, youth and adults need to realize that they are vulnerable to rapidly changing world and have to learn how to cope with it. For this they require continuous building of practical knowledge, attitude, skills and motivation that will lead them to a healthy lifestyle or healthy living. They need to avoid junk food habit and lead a lifestyle with healthy eating habit. The aim of this review is to find out the general food habits or dietary behavior of the people at present, the possible reasons behind the present food habit, effect of junk foods on health of children and adolescent, effect of junk food on academic behavior of children and adolescent an and how learning can help to avoid junk foods. 


\section{General food habits of the people}

\section{Normal food behaviour}

Traditionally the staple food of Indian population is cereal based. Cereal grains used are bajra, barley, millet, jowar, maize, ragi, rice, and wheat. The cereals are used in various forms like raw, flour, boiled, puffed, vermicelli, bread and germ to name a few. Pulses and legumes are used as the secondary food. These include bengal gram, pea, beans, green gram, horse grams, kheshari dal, lentil, rajmah, red gram, soyabean, etc. They are used either green, dry, roasted, powder, boiled, or in curry form in various parts of rural and urban India. The daily dose of micronutrients are provided by leafy vegetables like amaranth, bathua leaves, beet greens, bengal gram leaves, bottle gourd, brussels sprouts, cabbage, carrot leaves, cauliflower, celery leaves, colocasia leaves, coriandar leaves, drumstick leaves, curry leaves, fenugreek leaves, fetid cassia, ipomea leaves and stems, lettuce leaves, mustard leaves, parsley, pumpkin leaves, radish leaves, spinach leaves, susni sag, tamarind leaves, turnip leaves, and many more. (Gopalan, et.al.,1989).

Deaton and Drèze (2009) had compiled and quantified the nutritional behavior of Indian populace from National Sample Survey, which when plotted along the years from 1983 to 2005 shows the nutritional trend.

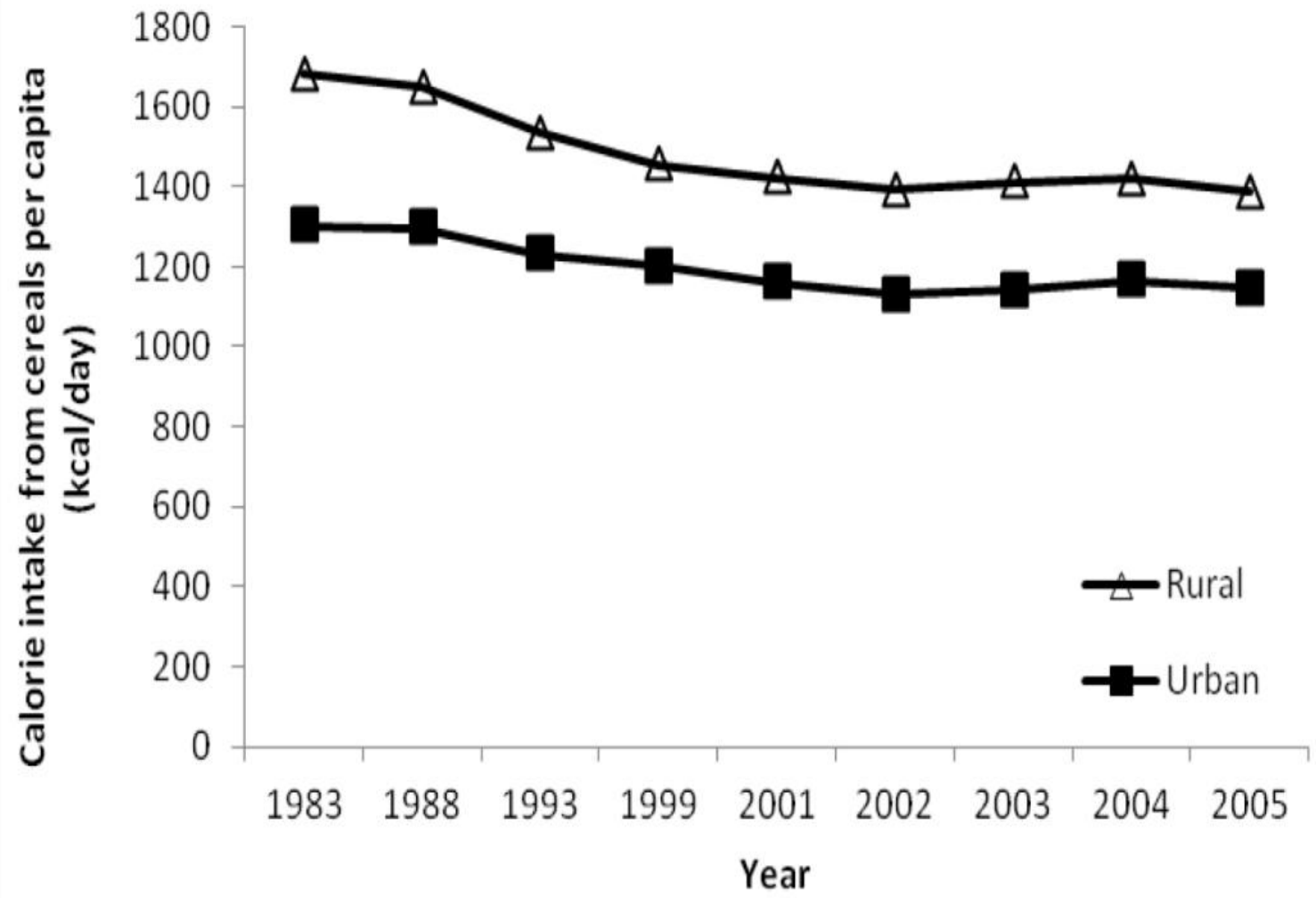

Fig. 1 Calorie intake from cereals (kcal/day) 


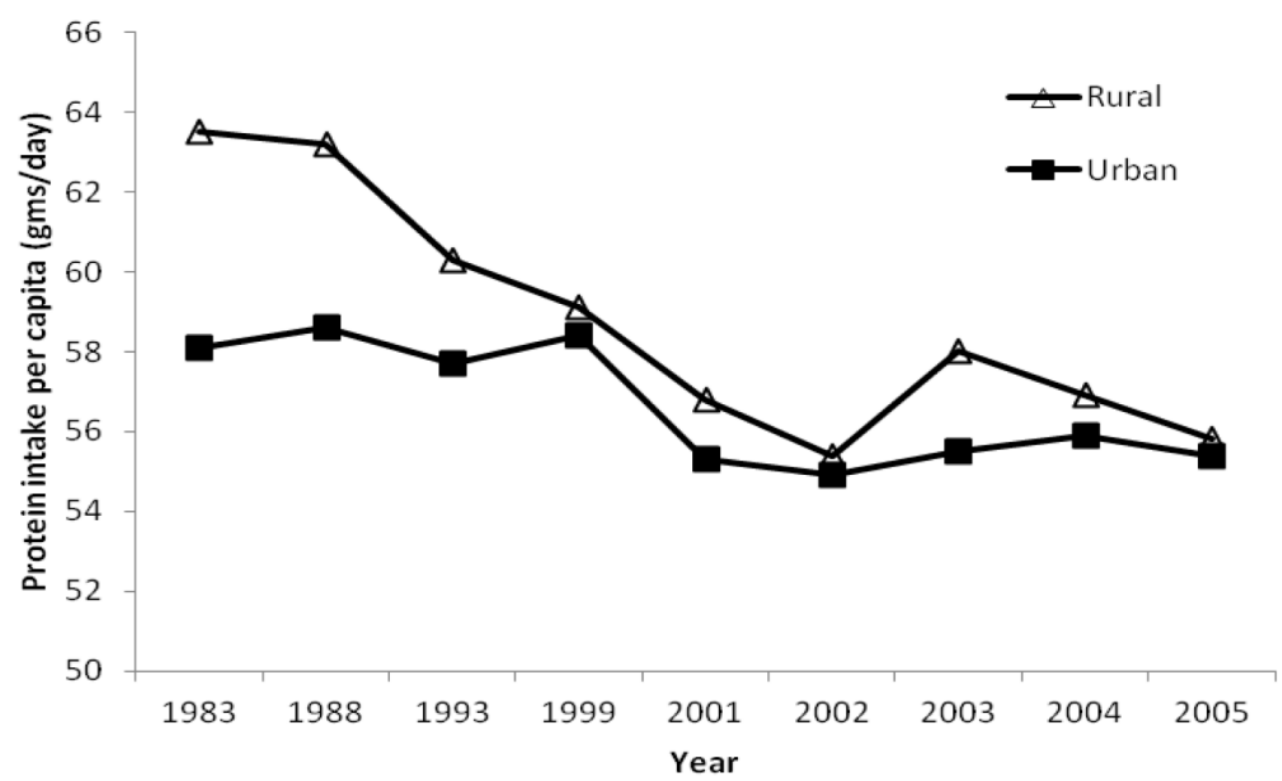

Fig. 2 Protein intake (gms/day)

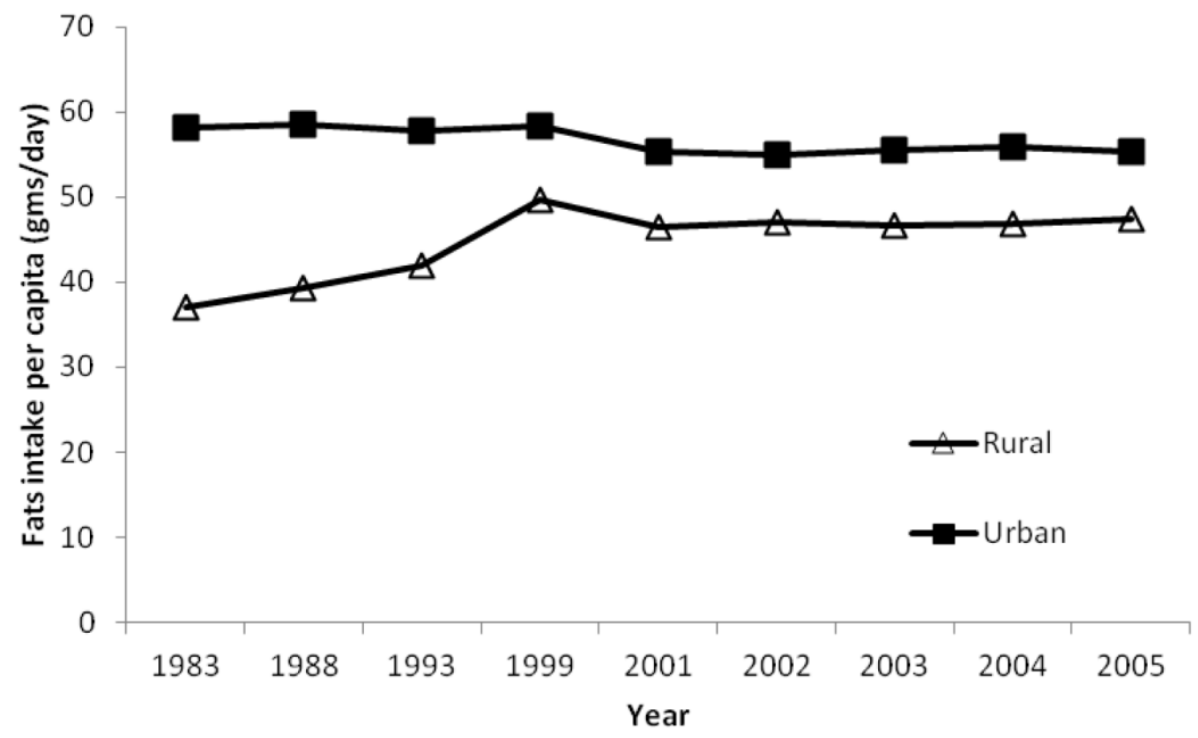

Fig. 3 Fat intake (gms/day)

The calorie intake from cereals in rural population is always found to be higher than the urban population in all ages, however the cereal intake declined in both rural and urban population. A steep decline is found in case of protein intake but in case of fat intake the urban population superseded the rural people. The most significant change in the fat intake behavior is that there is a slow but steady increase in fat intake among the rural folks compared to their urban counterparts.

\section{Junk food behaviour}

As per National Institute of Nutrition (NIN) "junk foods" are defined as "those containing little or no proteins, vitamins or minerals but are rich in salt, sugar, fats and are high in energy (calories)". (Gopalon, 2011). The term junk food is synonymous with food items with little or no nutritional values. In different 
nations, nutritional authorities termed foods with similar properties by several acronyms. WHO and several other countries are using the term HFSS i.e. "High in Fat, Salt and Sugar". In United States FMNV, i.e. "Food of Minimal Nutritional Value" is used. EDNPFC, i.e. "Energy Dense and Nutrient Poor Foods for Children" is used in Republic of Korea and "Energy Dense" foods is popularly used by certain associations and countries.

Modern lifestyle led by the school children of upper and lower primary is often found to influence the junk food consumption behavior of them (Andreyeva, et.al., 2011; Dixon, et. al., 2007). Snacks (Yoon and Lee, 2010), cookies, burgers, soda, pizza, etc. have been occupying the menu of adolescents. In a study conducted by Vinay et.al. (2012) revealed that $18 \%$ were taking junk food as an alternative to breakfast, $60 \%$ of individuals liked junk foods for their taste as it was one of the predominant factor for their choice.

\section{The possible reasons behind the present food habit}

The probable reasons for the junk food habit of children, adolescents or adults in the present days may be enumerated as time factor, convenience and easy availability, addictive nature, sedentary lifestyle, influence of media, urbanization and globalization, socio-economic condition, etc.

Time factor - Working mother may not have enough time to cook. So either they provide readymade food or give their children money to buy food from school canteen or local food outlets. In the busy life adults, adolescents and even children often skip their breakfast and become dependent on junk foods.

Easy availability - Junk foods are easily available in the market in readymade forms. Often the packets are made for a single serving. Junk foods such as potato wafers do not even need cooking or heating.

Addictive nature - Junk foods are very tasty and make us craving for eating them more and more. Taste enhancers like monosodiumglutamate (MSG) was found to possess addictive potential in experimental animals (Buzescu, et.al., 2013).

Sedentary lifestyle - At present, many people are engaged in sedentary activities like sitting, reading, socializing, watching television, playing video games, mobile phone, computer, etc, for much of the day with little or no vigorous physical exercises. Such lifestyle may encourage them to have readymade foods or junk foods (Pearson and Biddle,2011).

Influence of media and advertisement - Junk food advertisements use such colors, languages, images or mascots that are appealing to both children as well as their parents. Many advertisements especially of health drinks or other foods manipulate the parents in such a way that they think that buying that drink or food is inevitable for the well-being of their children. Many food manufacturers are often marketing many food products through toys, games, story books, educations materials to which the youngsters are getting more and more attracted.

Urbanization and globalization - Around the world the food systems are changing resulting in greater availability and diversity of food. These changes are closely associated with urbanization, increasing incomes, market liberalization and foreign direct investment. Competition among large multinational fast food and supermarket chains has bought a significant improvement in standard of food quality, safety, attractiveness, availability and access. There is a gradual shift in food culture which resulted in dietary consumption patterns and nutritional status that vary with the socio-economic strata (Kennedy, et. al., 2004).

Socio-economic condition - There may be relationship between junk food consumption and socioeconomic status. Lower socio-economic group of people may consume more poor-quality, energy dense, 
affordable foods (Kennedy, et. al., 2004). It has been found that adolescents who spend more time in study and do physical exercises, consume healthy food and those who give less time in study and have smoking habit, adopt a junk food patterns (Kourlaba, et. al., 2009).

\section{Effect of junk foods on health and education}

Several ingredients incorporated in the junk foods to make it palatable and un-resistible are known to impact health adversely. Numerous studies have established significant correlation with several noncommunicable diseases like diabetes, hypertension, heart diseases and cancer.

\section{Effects on physical health}

Obesity: Eating frequent junk foods cause teens and young adults to gain more weight and they face an increased risk of developing obesity. The incidence of child obesity has more than tripled in the past 30 years (Parveen, 2014). The prevalence of obesity among adolescents aged between 12 to 19 years has been increased from $5.0 \%$ to $18.1 \%$. Although obesity is primarily mediated by genetic, behavioral, and environmental factors, in recent time it is the result of caloric imbalance.

Diabetes: Obesity is found to be directly linked to insulin resistance that leads to type-2 diabetes of children (Seidell, 2000). In fact, it is treated as greater risk factor than alcohol consumption or sedentary lifestyle.

Cardiovascular diseases: Excessive salt intake increases the blood pressure which may in turn lead to heart failure. There are numerous additives those are added in the junk food. These ingredients can cause health problems. For example, monosodium glutamate (MSG) is a flavor enhancer commonly added to Chinese foods, canned vegetables, soups, and processed meats that cause hypothyroidism, headache, nausea, difficulty in breathing, drowsiness, rapid heartbeat and chest pain. (Sharma, 2013) Ingredients like aspartame acts as excitotoxin can stimulate the NMDA receptors in the brain. An analysis of the Coronary Artery Risk Development in Young Adults (CARDIA) study revealed a clear link with additives. (Steffen, et. al., 2005) Trans-fats, made from hydrogenated vegetable oil, can be found in margarine, biscuits, cakes and fast food. It can raise the level of our 'bad' cholesterol, significantly increasing the risk of atherosclerosis which blocks arteries, leading to heart disease and stroke (Chen, et. al., 2011).

\section{Effect on mental health}

A study by Sharma (2013) suggested that junk food consumption alters brain activity in a manner similar to addictive drugs like cocaine or heroin. After many weeks with unlimited access to junk food, the pleasure centers become decentralized, requiring more food for pleasure. Some ingredients of fast foods, like sugar, highly processed carbohydrates, saturated fats and trans-fats have addictive effects. The person craves for more for the same food in regular dose. The person becomes irritable, anxious and depressed when he or she cannot get it. It has been found that the risk for psychiatric distress and violent behavior may be increased among children and adolescents due to the excessive consumption of junk food (Zahedi, et. al., 2014).

Weight gain due to regular consumption of junk food may result in low self-esteem which can lead to consequences like depression. Depression may have negative impacts on all-round growth and development of children, their performance in school and social relationships.

Most of us know that junk food is unhealthy, of poor nutrition and is related to heart problems, high blood pressure, and a host of other health ailments. But still we consume junk foods. Actually, two main factors make us addicted to junk food. They are:

(i) The sensation of eating the food: This includes food's tastes (salty, sweet, sour, hot, yummy, etc.), smells, and how it feels in the mouth. The last quality is known as 
"orosensation". Emulsified foods like butter, chocolate, salad dressing, ice cream, and mayonnaise promote a salivary response that helps to lather your taste buds with goodness. Food companies and scientists are all combined to create the sensation that our brain associates with a particular food or drink. These sensations titillate our brain and coax into taking more dose of it.

(ii) The actual macronutrient makeup of the food: A perfect combination of salt, sugar, and fat in junk food excites our brain and make us crave for more. Junk food manufacturers are always in search of that perfect combination of salt, sugar, fat and crunchiness that excites our brain and titillates us to go back for more of it.

(iii) Rapid food meltdown and vanishing caloric density: Junk foods rapidly melt down in the mouth and vanish quickly. This sends a pseudo signal to the brain that our hunger is not yet satiated even though we are eating a lot of calories. The consequence is over eating (Clear, 2017).

\section{Effect on academic behavior}

A national survey of nearly 12,000 students in USA by several researchers at Ohio University found that children's academic performance becomes affected by daily consumption of junk food. Students who have consumed junk foods at least once a day have slower growth in math, reading and science skills than those who have not consumed (Von, 2007). A 2013 report by Action for Healthy Kids, a public-private partnership of more than 50 organizations showed that the cognitive ability of children has been improved when they started their day with a nutritious breakfast and later engaged in an hour of physical activity (Logi, et. al., 2010).

Researches show that there is increased hyperactivity in children due to consumption of food additives like sodium benzoate, artificial food colours etc. present in many processed foods marketed to children. This hyperactivity negatively impact on students' learning. Obese and overweight children and young may experience stigmatization, discrimination, peer-exclusion and other psychosocial outcome which altogether may resist their ability to do well at school (Utter, et. al., 2009).

Junk food and foods with high sugar content deplete energy levels and the ability to concentrate for extended period of time among children. It affects their performance in school and extracurricular activities (http://healthyeating.sfgate.com/junk-food-affects-children-5985.html., 2017).

\section{How learning can help to avoid junk foods}

Our days should have breakfast and meal containing enough cereals, proteins, fats, fruits and leafy vegetables and fortify our body so that we will not get an urge for junk food. Staying healthy is not abhorring food and staying unrealistically thin or depriving our body form the food we crave for. Food with enough leafy vegetable fortifies us with micronutrients like vitamins and minerals. We should consume meals cooked at our home, and reduce intake of processed sugar and refined carbohydrates. Whatever we use first we should know about foods, nutrition, balanced diets, etc.

\section{Food Literacy}

Food literacy is a term that refers to "the degree to which people are able to obtain, process, and understand basic information about food in order to make appropriate health decisions." Food literacy is more than food knowledge. It encompasses the motivation to apply nutrition information to food choices. The various components of food literacy are proposed by Summer (2013). It includes (i) learning of concept of nutritional facts and figures, (ii) applying that knowledge in selection, preparation and consumption of right food, (iii) to have ability and motivation to apply and disseminate the information and knowledge to others. 


\section{Role of educational institutions}

School meal programs like "Midday Meal Programs" presently running all over India may be a tool to educate children what a healthy meal looks like. Healthy eating patterns in childhood and adolescence promote optimal childhood health, growth, and intellectual development. It can prevent chronic health problems, such as iron deficiency anemia, obesity, eating disorders, and dental caries; and may prevent long-term health problems, such as coronary heart disease, cancer, and stroke. School can literate children about healthy food in the class, caution the children to avoid junk foods. Honorable High court of Delhi had issued a directive to limit the availability and exposure of junk foods to children within radius of 500 yards of school premises. At present the chapter of nutrition is included in the Life Science book of $8^{\text {th }}$ standard. State Governments may take initiatives to include the chapter of nutrition well before $8^{\text {th }}$ standard to educate and sensitize the children in lower primary school.

Some private organizations are coming forward to make the schools in India junk food free. For instances, the Consumer association of India (CAI), Chennai, launched a campaign to raise awareness among school children. The Consumer Guidance Society of India (CGSI) has approached several schools in Mumbai to start a parent-teacher association that will manage the menu and operations of the school canteen (https://www.telegraphindia.com/1090216/jsp/atleisure/story 10542240.jsp., 2009).

\section{Role of parents}

Parents should practice cooking healthy food at home, teach their children how to shop, purchase fish and vegetables, cook and enjoy cooking rather than frequent the junk food shops or vendors. Children should find more joy in the subtlety of the tastes in home cooked foods rather than the mechanical and repetitive taste of junk foods. Parents should be a role model and show their children the joys of home cooking. They should encourage their children to cook food and appreciated that food to motivate the children.

Parent should avoid words like "dieting", instead, it should be replaced with more positive words like "nutritious food", "energetic food", "healthier food", etc. Good eating practice must be practiced at home at the dining table. Distractions like viewing TV while eating is a major problem with the children. They are not aware of what they are engulfing and mechanically they go on eating excessive junk foods. Children should dine with the family members discussing about the foods served and their qualities or variations. Traditional foods should be encouraged on the dining table. Ending a meal with fresh fruits or salad should be mandatory. Think food. Talk food. Eat food. Enjoy food.

\section{Food movement}

To make the masses food literate various channels of learning have already been adopted by the society at large. TV channels dedicated to food and living have been on air for a long time. Their high TRP rating is an evidence of the popularity enjoyed by those channels. Chef competition, culinary shows, visit to organic farm, workshop on food and cooking competition at University level may be used to inform and popularize foods. Films like Food Inc., Supersize me, Forks over knives, Kungfu Chef, etc. educate us but with enjoyments.

We can learn about various food ingredients and their manufacturing processes from documentaries shown in channels like Discovery, History, Travel X, Fox Travel, Food and Livings, etc.

\section{Conclusion}

Healthy lifestyle is utmost necessity of our life. To achieve this requirement we should follow the proper food habit throughout our lives. But due to the globalization and modernization there is rapid changes in food consumption behaviour worldwide and children and adolescents and adults as well are becoming more and more addicted to junk foods. As a result there are various problems on their physical health, mental health, academic behavior, etc. To overcome this situation and to achieve healthy body and mind there is need for proper learning to acquire adequate awareness, knowledge, attitude and motivation of the 
people .In this regard food literacy has a great role. It helps and encourages in learning to prepare healthy meals, to understand the healthy food sources, to prevent or resist ourselves from being misguided by various marketing messages and to practice healthy eating habit. Educational institution, parents, media must have positive role in this regard. Above all, we all should acquire the ability of reflective and critical thinking so that we may become self-reliant and able to direct, manage, and control ourselves in food consumption. To avoid junk food we should have proper reasons, should make a plan, should be confident, should take action and choose proper environment, should exercise, and finally enjoy the food.

\section{References}

1.Andreyeva, T. Kelly, I. R and Harris, J. L.(2011). Exposure to food advertising on television: associations with children's fast food and soft drink consumption and obesity, Economics and Human Biology, 9(3), 221-33.

2.Buzescu, A., Cristea, A. N., Avram, L. and Chiriţă, C. (2013). The addictive behaviour induced by food monosodium glutamate. Experimental study. Romanian Journal of Medical Practice. 229-233.

3.Chen, C. L., Tetri, L. H., Neuschwander-Tetri, B. A., Huang, S. S. and San, H. J. (2011). A mechanism by which dietary trans fats cause atherosclerosis, The Journal of Nutritional Biochemistry, 22(7), 649-55. Clear, J. (2013). What Happens to Your Brain When You Eat Junk Food [Internet - cited 2017 May 10]. Available from: http://jamesclear.com/junk-food-science.

4.Deaton, A. and Drèze, J. (2009). Food and nutrition in India: facts and interpretations, Economic and Political Weekly, 2009, 42-65.

5.Dixon, H. G., Scully, M. L., Wakefield, M. A., White, V. M. and Crawford, D. A. (2007). The effects of television advertisements for junk food versus nutritious food on children's food attitudes and preferences, Social Science and Medicine, 65(7), 1311-23.

6.Gopalan C, Sastri, B. V. R and Balasubramanian, S. C. (1989). Nutritive Value of Indian Foods, National Institute of Nutrition, Indian Council of Medical Research (Hyderabad).

7.Gopalan, C.(2011). Dietary Guidelines for Indians - A manual [Internet]. 2nd ed. India: National Institute of Nutrition, Hyderabad.

8. $\quad$ http://www.bbc.co.uk/science/0/22019289. (2013 Apr 19). Healthy living: How to live longer. BBC Science [Internet - cited 2017 May 10].

9. http://healthyeating.sfgate.com/junk-food-affects-children-5985.html. (2017). How Junk Food Affects Children. [cited 2017 May 10].

10. https://www.telegraphindia.com/1090216/jsp/atleisure/story_10542240.jsp. (2009).Wanted, child lock for junk food, [Internet - cited 2017 May 10].

11. Kennedy, G., Nantel, G. and Shetty P. (2004). Globalization of Food Systems in Developing Countries: Impact on Food Security and Nutrition, Food \& Agriculture Org. of the U. N. (Rome).

12. Kourlaba, G., Panagiotakos, D. B., Mihas, K., Alevizo, A., Marayiannis, K. and Mariolis, A. (2009). Dietary patterns in relation to socio-economic and lifestyle characteristics among Greek adolescents: a multivariate analysis, Public Health Nutrition, 12(09), 1366-72.

13. Logi, K. Á., Dóra, S. I. and Allegrante, J. P. (2010). Health behavior and academic achievement among adolescents: the relative contribution of dietary habits, physical activity, body mass index, and self-esteem, Health Education and Behavior. , 37(1), 51-64. 
14. Pearson, N. and Biddle, S. J. (2011). Sedentary behavior and dietary intake in children, adolescents, and adults: a systematic review. American Journal of Preventive Medicine, 41(2):178-88.

15. Praveen, R. (2014). Endocrinology and diabetes mellitus: What's new in it?, World Journal Pharmacy and Pharmaceutical Sciences, 3(5), 1340-50.

16. Schaumburg, H. H., Byck. R., Gerstl, R. and Mashman, J.H. (1969). Monosodium L-glutamate: its pharmacology and role in the Chinese restaurant syndrome, Science, 163(3869), 826-8.

17. Seidell, J. C. (2000). Obesity, insulin resistance and diabetes-a worldwide epidemic, British Journal of Nutrition, 83(S1), 5-8.

18. Sharma, V. ((2013). Adolescent' s knowledge regarding harmful effects of junk food. IOSR Journal of Nursing and Health Sciences, 1(6), 01-4.

19. Steffen, L. M., Kroenke, C. H., Yu, X., Pereira. M. A., Slattery, M. L. and Van, H. L. (2005). Associations of plant food, dairy product, and meat intakes with 15-y incidence of elevated blood pressure in young black and white adults: the Coronary Artery Risk Development in Young Adults (CARDIA) Study, The American Journal of Clinical Nutrition, 82(6), 1169-77.

20. Sumner, J.(2013). Food literacy and adult education: learning to read the world by eating. The Canadian Journal for the Study of Adult Education (Online), 2013, 25(2):79.

21. Utter, J., Scragg, R., Percival, T. and Beaglehole, R. (2009). School is back in New Zealand-and so is the junk food. New Zealand Medial Journal, 122(1290), 5-8.

22. Vinay, G. J., Sriram S., Kannabiran, K. and Seenivasan, R. (2012). Student's perspective on junk foods: Survey. Sudanese Journal of Public Health, 7(1), 21-5.

23. Von, H. P. T., Powell, B., Downey, D. B. and Rowland, N. J. (2007). The Effect of School on Overweight in Childhood: Gain in Body Mass Index During the School Year and During Summer Vacation, American Journal of Public Health, 97(4), 696-702.

24. Yoon, J. S. and Lee, N. J. (2010). Dietary patterns of obese high school girls: snack consumption and energy intake, Nutrition Research and Practice, 4(5), 433-7.

25. Zahedi, H., Kelishadi, R., Heshmat, R., Motlagh, M. E., Ranjbar, S. H. and Ardalan, G. (2014). Association between junk food consumption and mental health in a national sample of Iranian children and adolescents: the CASPIAN-IV study, Nutrition, 30(11), 1391-7. . - - 0 - 